\title{
Surface TeXTure Quality OF Models ManufaCtured by AdDITIVE TECHNOLOGY FUSED DEPOSITION MODELING
}

\author{
Paweł Zmarzły, Stanisław Adamczak, Tomasz Kozior, Damian Gogolewski
}
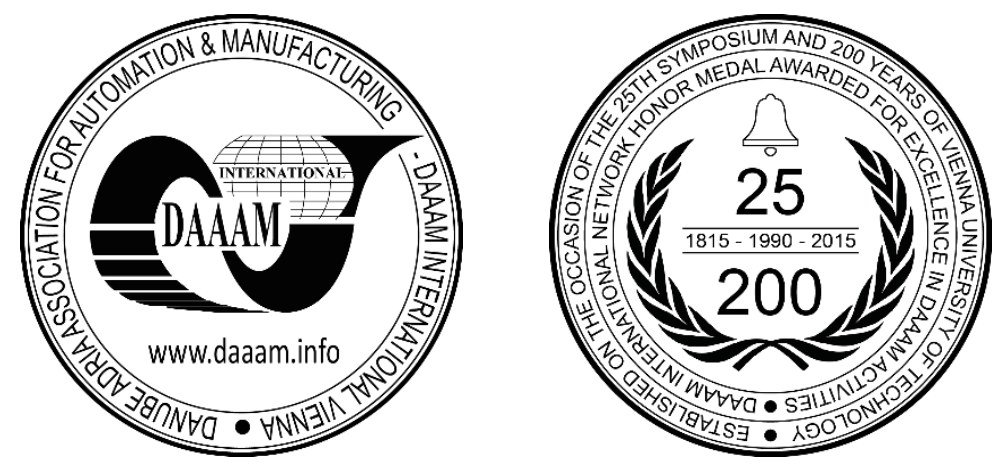

This Publication has to be referred as: Zmarzly, P[awel]; Adamczak, S[tanislaw]; Kozior, T[omasz] \& Gogolewski, D[amian] (2018). Surface Texture Quality of Models Manufactured by Additive Technology Fused Deposition Modeling, Proceedings of the 29th DAAAM International Symposium, pp.0853-0859, B. Katalinic (Ed.), Published by DAAAM International, ISBN 978-3-902734-20-4, ISSN 1726-9679, Vienna, Austria

DOI: $10.2507 / 29$ th.daaam.proceedings. 123

\begin{abstract}
The additive technology of Fused Deposition Modeling (FDM) can be applied in production of various elements, including cylindrical parts rotating around an axis of rotation. The main goal of research presented in this paper was the assessment of the main technological parameter of the FDM technology, i.e. a print-out direction on roundness and waviness deviations of cylindrical elements. Research was entirely performed in the laboratories of the Chair of Mechanical Technology and Metrology. Details being analyzed were designed in order to match typical casting models. These elements were made of the ABS P430 material with use of the "Dimension 1200es" printer by Stratasys. Profiles of roundness and waviness in the manufactured cylindrical elements were measured by means of the Talyrond 365 measuring system. Roundness deviation was analyzed within the range of 2-15 undulation per revolution, while waviness deviation within the range of 16-50 undulation per revolution. Research showed that a printing direction had the significant impact on deviation values of roundness and waviness of the elements being manufactured.
\end{abstract}

Keywords: FDM; ABS P430; roundness; waviness

\section{Introduction}

One of the most popular additive methods is the technology of Fused Deposition Modeling (FDM) that has been developed since the early 1980s. The main advantage of this method is use of widely available and cheap plastics, such as ABS, PC, PC-ABS, ASA or PEI, to construct engineering prototypes. As a result, mechanical properties of printed elements are similar to those of injection-moulded models. High popularity of the FDM method, low production costs and satisfactory mechanical, metrological and tribological properties [1] of manufactured elements make this method be applied in various fields of industry. The said technology can be successfully used to develop functional prototypes [2] and thanks to filament of various colours it is possible to significantly improve aesthetic features of performed products [3]. Additionally, continuous development and improvement of 3D printers using FDM technologies enable production of ready-to-use machines and mechanisms, for which subsequent processing is not needed [4]. Thanks to short time needed for element production, the FDM technology can be widely used in the casting industry for short-lasting production of casting models and molds [5], while application of low-melting materials enables this technology to be successfully used in casting of sophisticated individual elements by using the method of lost-material casting. 
The technological parameters of the FDM technology have the impact on dimensional accuracy [6-7] and mechanical properties [8] of manufactured elements. Among the most important technological parameters we can distinguish printing direction (distribution at a work platform), infill material and thickness of a layer being built. There are various pieces of research aiming to determine the impact of technological parameters on manufacturing accuracy and accuracy of manufactured elements [9], whereas there is no research aiming to determine the impact of these parameters on roundness and waviness deviations of cylindrical elements. Accuracy of the FDM technology enables production of round elements that can rotate around an axis of rotation. In case of cylindrical details minimization of roundness deviation values is pursued, as they may impede assembly or have the impact on operation of mechanisms rotating around an axis of rotation [10], [11], whereas excessive waviness deviation values in rolling bearing races may contribute to occurrence of excessive vibration values [12]. As a result, it should be thoroughly analyzed, which values of the FDM technology will enable production of cylindrical elements with satisfactory values of roundness and waviness deviations. This problem is going to be discussed in this paper.

\section{Research procedure}

The main goal of experimental research was the assessment of the impact of a sample distribution direction on a work platform in a "Dimension 1200es" printer, using the FDM technology, on values of roundness and waviness deviations. The first stage of the research procedure was the CAD design of cylindrical samples, whose shapes match typical casting models. The file was written in the STL format with so called fine resolution, that was subsequently converted by 3D printer software in order to divide it into $0.25 \mathrm{~mm}$ thick layers. Then the series of samples were performed, considering three printing directions. The samples were performed in Laboratory of Unconventional Manufacturing Technology. After sample cleansing metrological tests were performed. Shape contours were measured by means of the Talyrond 365 measuring system present in the Laboratory of Computer Measurement of Geometric Quantities.

\subsection{The Fused Deposition Modeling technology}

FDM is currently one of the most popular, cheapest and fastest [13] technologies in the rapid prototyping method market. It occurs as applying layers of a melted plastic on the platform, most often in the form of spool-wound filament delivered to vertically positioned printheads. Printheads heat the material to the temperature slightly lower than the melting temperature in order to process it to the quasi-solid state. When a printhead is moving, the material is extruded through a nozzle and it sediments on the platform in the form of a thin thread. After cooling the thermoplastic material takes the form previously shaped in the process of sedimentation. This method requires creation of support structures, resulting in significantly limited model manufacturing capabilities. Though more and more advanced soluble support materials are being introduced, their application remains limited.

A "Dimension 1200es" printer by Stratasys was used to manufacture samples for this paper. This machine enables production of elements made of plastics and with maximum size of 254 x 254 x $305 \mathrm{~mm}$ [14]. At the figure 1 we can see the $3 \mathrm{D}$ printer that was used to build sample models. It is situated at the Kielce University of Technology.

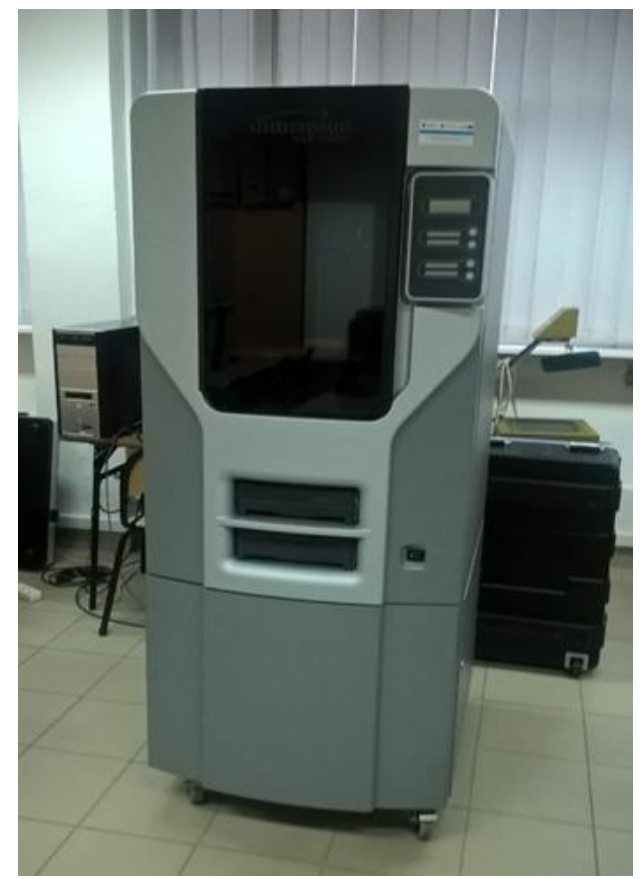

Fig. 1. 3D printer - Dimension 1200es 


\subsection{Samples used for tests}

The samples used for tests were designed in the form of conical frustum with a base of $\phi 20 \mathrm{~mm}$, wall inclination angle of $1^{\circ}$ and height of $25 \mathrm{~mm}$. The samples were situated on the printer work platform at three different angles, i.e. $0^{\circ}$ (no. 1), $45^{\circ}$ (no. 2) and $90^{\circ}$ (no. 3). Five samples were produced for each printing direction being analyzed. In total fifteen samples were tested. The sample view and the schematic layout of sample distribution on the printer work platform were shown at the figure 2 .
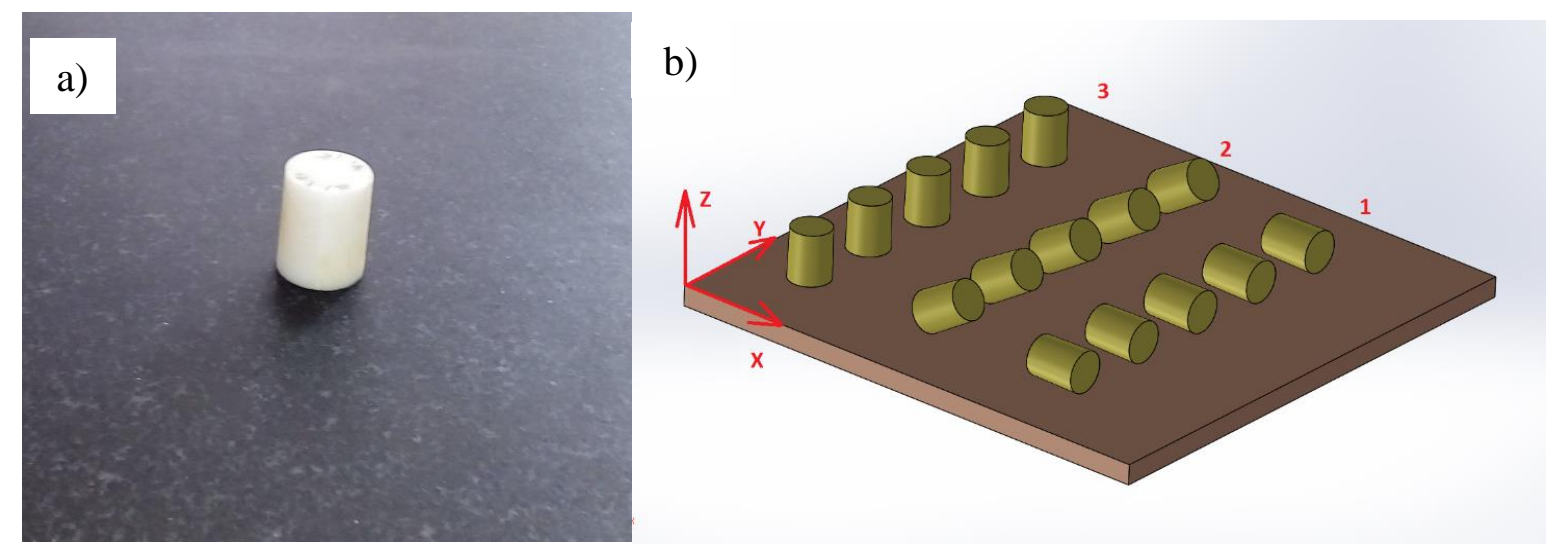

Fig. 2. Samples used for tests: a) view of the printed sample, b) distribution of samples on the printer work platform

The samples were manufactured of the ABS P430 material with applied thickness of the built layer being $0.25 \mathrm{~mm}$. Thanks to its satisfactory mechanical properties, ABS P430 is widely used in the automotive, household appliances and aviation industries. The table 1 shows the most important parameters of the ABS P430 material.

\begin{tabular}{|c|c|c|}
\hline Mechanical properties & Values & Standard \\
\hline Tensile strength & $37 \mathrm{MPa}$ & ASTM D638 \\
\hline Young's modulus & $2,320 \mathrm{MPa}$ & ASTM D638 \\
\hline IZOD Impact, notched & $106 \mathrm{~J} / \mathrm{m}$ & ASTM D256 \\
\hline Tensile Elongation at Break & $6 \%$ & ASTM D638 \\
\hline Tensile Elongation at Yield & $2 \%$ & ASTM D638 \\
\hline
\end{tabular}

Table 1. Some mechanical properties of ABS P430 [14]

\subsection{Measurement of roundness and waviness contours}

Measurement of roundness and waviness profiles of the samples manufactured by means of the FDM technology was made with use of the Talyrond 365 measurement system situated in the Laboratory of Computer Measurement of Geometric Quantities at the Kielce University of Technology. This is a measurement system based on the radius change measurement method, that have high measuring accuracy [15], [16]. The figure 3 shows the photographs of the measurement system used for tests.

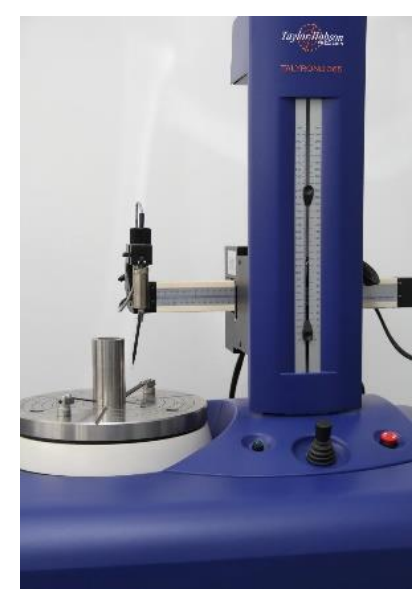

Fig. 3. Measuring system - Talyrond 365 
The primary profile was measured at half-height of the manufactured samples. Then the measured profile was filtered by means of a Gaussian filter. The roundness and waviness deviations were determined on the basis of the reference circle determined by means of the method of least squares. Roundness deviation was tested within the range of 2-15 undulation per revolution, while waviness deviation within the range of 16-50 undulation per revolution.

The measured deviations were marked with the RONt symbol. In order to perform a more thorough analysis of measured contours harmonic analysis was used to be able to determine a dominant element of unevenness. The table 2 shows the basic technical specification of the Talyrond 365 measuring system by Taylor Hobson.

\begin{tabular}{|c|c|}
\hline \multicolumn{2}{|c|}{ Measuring Capacity } \\
\hline Maximum Component Diameter & $\varnothing 400 \mathrm{~mm}$ \\
\hline Maximum Component Height & $300 \mathrm{~mm}$ \\
\hline \multirow{2}{*}{ Maximum Component Weight } & Auto Center and Level: $75 \mathrm{~kg}$ \\
& Manual Center and Level: $20 \mathrm{~kg}$ \\
\hline \multicolumn{2}{|c|}{ Spindle axis } \\
\hline Velocity of rotation & $0.6,1,2,6,10 \mathrm{rpm}$, bi-directional \\
\hline Radial limit of error (height above table) & $+/-(0.02 \mu \mathrm{m}+0.0003 \mu \mathrm{m} / \mathrm{mm})$ \\
\hline Axial limit of error (radius from center) & $+/-(0.02 \mu \mathrm{m}+0.0003 \mu \mathrm{m} / \mathrm{mm})$ \\
\hline Number of data points & $18,000 \mathrm{maximum}$ \\
\hline \multicolumn{2}{|c|}{ Gauge Resolution } \\
\hline Resolution & $1.3 \mathrm{~nm}($ range $0.08 \mathrm{~mm})$ \\
\cline { 2 - 2 } & $6.3 \mathrm{~nm}($ range $0.41 \mathrm{~mm})$ \\
\cline { 2 - 2 }
\end{tabular}

Table 2. Technical specification of Talyrond 365 [17]

\section{List and analysis of test results}

Test results were grouped depending on a sample print-out direction and shown in the table 3. A-e symbols were used to assign sample numbers (the same distribution), while digits were used to assign a sample distribution direction on the machine-building platform. The samples marked with 1 were made at an angle of $0^{\circ}$, with 2 at an angle of $45^{\circ}$ and with 3 at an angle of $90^{\circ}$.

Roundness and waviness deviations were marked with the RONt symbol, while the range of 2-15 upr (undulation per revolution) means roundness deviation and the range of 16-50 upr means waviness deviation. The " $\bar{x}$ " symbol was used for a mean value, while the " $s$ "symbol for an average standard deviation for measured deviations.

\begin{tabular}{|c|c|c|c|c|c|c|c|c|c|c|c|}
\hline \multirow{2}{*}{\multicolumn{2}{|c|}{$\begin{array}{c}\text { Sample } \\
\text { no. }\end{array}$}} & \multicolumn{2}{|c|}{ RONt, $\mu \mathrm{m}$} & \multirow{2}{*}{\multicolumn{2}{|c|}{$\begin{array}{c}\text { Sample } \\
\text { no. }\end{array}$}} & \multicolumn{2}{|c|}{ RONt, $\mu \mathrm{m}$} & \multirow{2}{*}{\multicolumn{2}{|c|}{$\begin{array}{c}\text { Sample } \\
\text { no. }\end{array}$}} & \multicolumn{2}{|c|}{ RONt, $\mu \mathrm{m}$} \\
\hline & & \multirow{2}{*}{$\begin{array}{c}\begin{array}{c}\text { 2-15, } \\
\text { upr }\end{array} \\
128.86\end{array}$} & \multirow{2}{*}{$\begin{array}{c}\begin{array}{c}\text { 16-50, } \\
\text { upr }\end{array} \\
94.01 \\
\end{array}$} & & & \multirow{2}{*}{$\begin{array}{c}\begin{array}{c}\text { 2-15, } \\
\text { upr }\end{array} \\
64.51\end{array}$} & \multirow{2}{*}{$\begin{array}{c}\begin{array}{c}\text { 16-50, } \\
\text { upr }\end{array} \\
74.37 \\
\end{array}$} & & & \multirow{2}{*}{$\begin{array}{c}\begin{array}{c}\mathbf{2 - 1 5}, \\
\text { upr }\end{array} \\
80.37 \\
\end{array}$} & \multirow{2}{*}{$\begin{array}{c}\begin{array}{c}\mathbf{1 6 - 5 0}, \\
\text { upr }\end{array} \\
71.4 \\
\end{array}$} \\
\hline \multirow{5}{*}{$\begin{array}{c}1 \\
\left(0^{\circ}\right)\end{array}$} & $\mathrm{a}$ & & & \multirow{5}{*}{$\begin{array}{c}2 \\
\left(45^{\circ}\right)\end{array}$} & $\mathrm{a}$ & & & \multirow{5}{*}{$\begin{array}{c}3 \\
\left(90^{\circ}\right)\end{array}$} & $\mathrm{a}$ & & \\
\hline & $\mathrm{b}$ & 139.39 & 86.06 & & $\mathrm{~b}$ & 75.7 & 83.69 & & $\mathrm{~b}$ & 73.76 & 74.35 \\
\hline & c & 115.55 & 100.22 & & $\mathrm{c}$ & 64.77 & 72.95 & & $\mathrm{c}$ & 75.34 & 77.24 \\
\hline & $\mathrm{d}$ & 132.24 & 93.19 & & $\mathrm{~d}$ & 66.62 & 87.75 & & $\mathrm{~d}$ & 83.17 & 69.84 \\
\hline & $\mathrm{e}$ & 146.2 & 95.78 & & $\mathrm{e}$ & 72.23 & 91.41 & & $\mathrm{e}$ & 75.79 & 68.93 \\
\hline \multicolumn{2}{|c|}{$\bar{x}$} & 132.448 & 93.852 & \multicolumn{2}{|c|}{$\bar{x}$} & 68.766 & 82.034 & \multicolumn{2}{|l|}{$\bar{x}$} & 77.686 & 72.352 \\
\hline \multicolumn{2}{|c|}{$s$} & 11.573 & 5.134 & \multicolumn{2}{|c|}{$s$} & 4.969 & 8.133 & \multicolumn{2}{|l|}{$s$} & 3.930 & 3.421 \\
\hline
\end{tabular}

Table 3. Test results

While analyzing test results shown in the table 3, it can be concluded that the largest values of roundness and waviness deviations were obtained for samples manufactured at the angle of $0^{\circ}$. For these results we can also observe significant disparities for measured values, proven by large values of standard deviation.

The smallest values of roundness deviations were obtained for samples manufactured at the angle of $45^{\circ}$, while for waviness these were samples manufactured at the angle of $90^{\circ}$. Measured values of roundness and waviness deviations for samples situated on the work platform at the angle of $90^{\circ}$ are characterized by the high level of cohesion (small values of standard deviation).

In order to perform the more thorough analysis of shape contours for the samples made with use of the FDM technology the figures below show the measured contours of roundness and waviness of given samples, followed by harmonic analysis of measured profiles. 

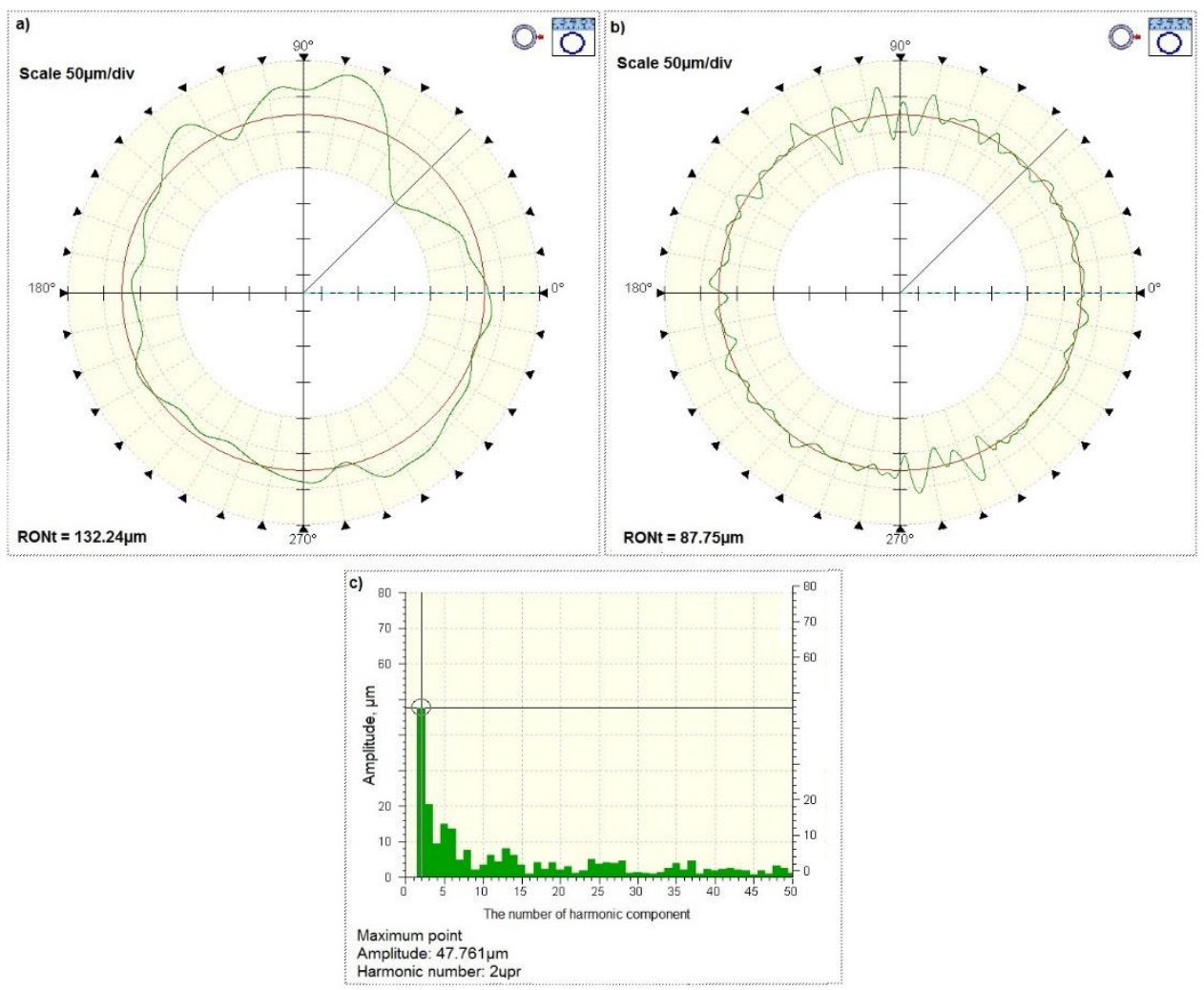

Fig. 4. Profiles measured for the sample manufactured at the angle of $0^{\circ}(1 \mathrm{~d})$, where:

a) roundness profile analyzed within the range of $2-15$ upr,

b) waviness profile analyzed within the range of 16-50 upr,

c) bar chart of amplitudes for certain harmonic components of the profile being measured.

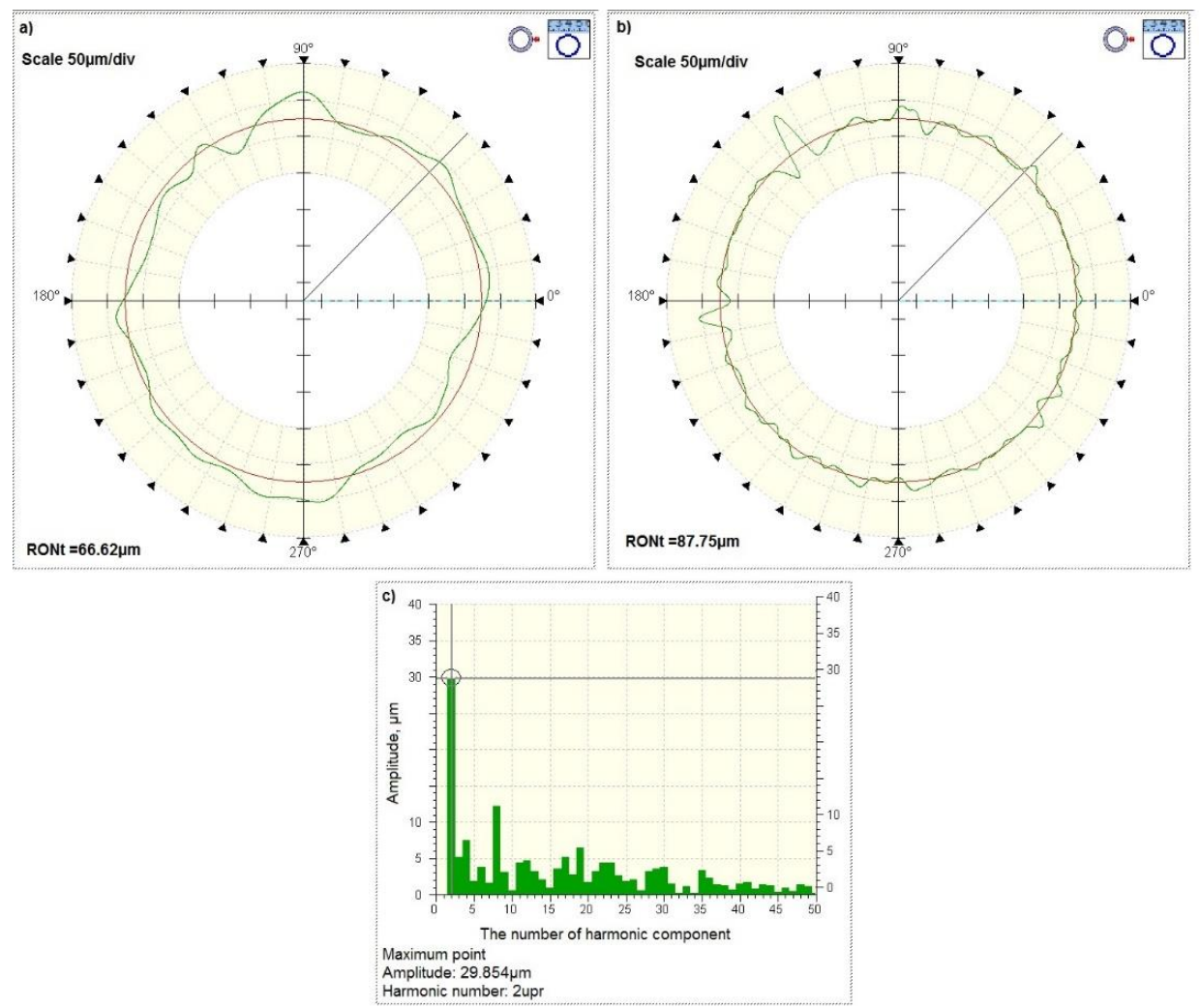

Fig. 5. Profiles measured for the sample manufactured at the angle of $45^{\circ}(2 \mathrm{~d})$, where:

a) roundness profile analyzed within the range of 2-15 waves/revolution,

b) waviness profile analyzed within the range of $16-50$ waves/revolution,

c) bar chart of amplitudes for certain harmonic components of the profile being measured. 


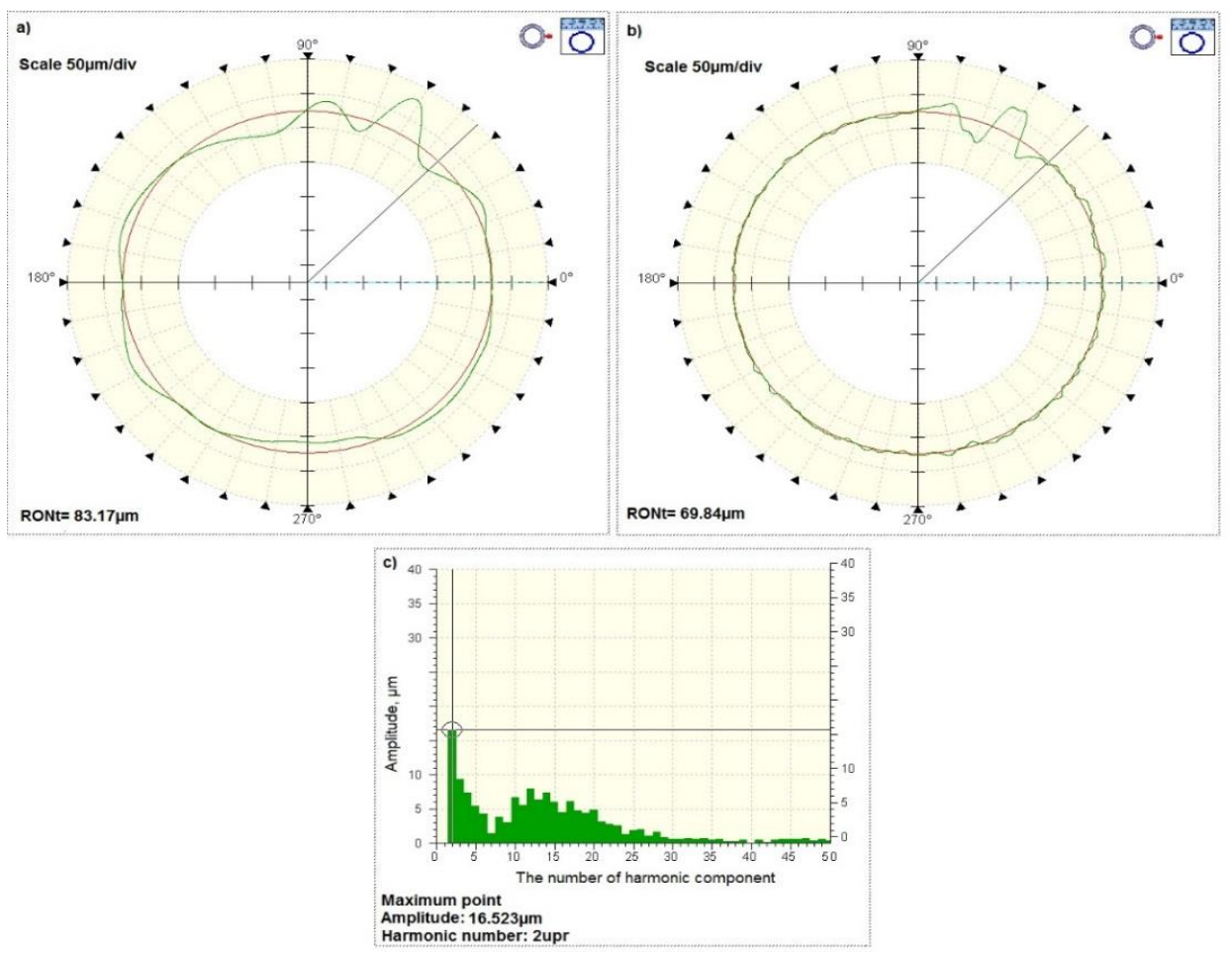

Fig. 6. Profiles measured for sample manufactured at the angle of $90^{\circ}(3 \mathrm{~d})$, where: a) roundness profile analyzed within the range of 2-15 waves/revolution,

b) waviness profile analyzed within the range of $16-50$ waves/revolution,

c) bar chart of amplitudes for certain harmonic components of the profile being measured.

While analyzing the contours of roundness and waviness for the sample manufactured at the angle of $0^{\circ}$ (fig. $4 \mathrm{a}$ and fig. 4b), we can conclude that the measured form deviate from an ideal circle to the largest extent among all analyzed samples. The profiles show significant surface unevenness that may result from the layered structure of the analyzed element. Let us add that subsequent layers of the material were administered along the sample axis (see fig. 2, the $\mathrm{Z}$ building axis). This can be seen at the fig. $4 \mathrm{~b}$ showing the waviness profile for the tested sample. Harmonic analysis of the measured profile showed that the second component was a dominant harmonic component, proving that the shape of the manufactured element is similar to an oval.

In contrast, the samples manufactured at the angle of $45^{\circ}$ show smaller values of roundness and waviness deviations. We can also detect marks of printing (fig. 5a and fig. 5b, the so called stairs step effect), however they are significantly less visible than for samples manufactured at the angle of $0^{\circ}$. While interpreting the chart of harmonic components (see fig. 5c), we can see that the second component is a dominant component of unevenness.

The smallest value of waviness deviation was found in samples manufactured at the angle of $90^{\circ}$ (fig. $6 \mathrm{~b}$ ). In the measured profile of the "3D" sample roundness we can see the evident "stairs" in the profile, that significantly increase the value of the deviations being analyzed. Such nature of unevenness may result from the initial movement of the printhead that started and finished its movement (course) in a particular location. While analyzing the chart of harmonic components of the tested profile (fig. 6c), we can see that the second component also reaches a dominant value, however harmonic components tested within the range of 8-23 show significant values, proving large the impact of waviness.

\section{Conclusion}

Additive technologies become more and more popular. One of the most popular additive technology is FDM based on deposition of thermoplastic materials. Thanks to its high accuracy, FDM can be used in production of end-use machine parts without need to subsequently process them. There are many research papers aiming to assess measurement accuracy of elements manufactured with use of the FDM technology, however there is no research focusing on the detailed shape analysis of cylindrical elements. In case of functional elements that rotate around an axis of rotation or reciprocate their roundness or waviness deviation should be tested.

The main goal of research presented in this paper was to assess the impact of a printing direction, using the FDM technology, on values of roundness and waviness deviations in manufactured samples. Shapes of samples matched typical casting models. The series of 15 samples (5 samples for each printing direction) were manufactured for the test purposes. The test results showed that the smallest values of tested deviations were found for samples manufactured at the angle of $90^{\circ}$. Let us add that print-out time for this direction is the longest. 
In contrast, the shortest production time of samples is obtained, when they are located on the work platform at the angle of $0^{\circ}$ (the sample axis is located parallelly to the building plane), however roundness and waviness deviations in these samples were the largest. The samples manufactured at the angle of $45^{\circ}$ seem to be something in between, because values of the measured deviations are satisfactory, while print-out time remains short.

Summing up the test results, we should state that a printing direction with use of the Fused Deposition Modeling technology has the significant impact on values of roundness and waviness deviations and it should be considered during production of cylindrical elements with use of this technology, as excessive values of shape deviations may generate vibrations in rotating parts of machines. Moreover, this may impede the assembly procedure, being of particular importance in the casting industry.

Conducting subsequent research, the authors of this paper are going to test other PLA-based building materials used together with the FDM technology. Additionally, shape deviations in cylindrical elements manufactured with use of other additive technologies (e.g. SLS, PJM and SLM) will be tested. Later plans include research aiming to test application of additive technologies in production of rolling bearing elements, in which values of roundness and waviness deviations are of great applied importance.

\section{Acknowledgments}

The paper has been elaborated within the framework of the research project entitled "Theoretical and experimental problems of integrated 3D measurements of elements' surfaces", reg. no.: 2015/19/B/ST8/02643, ID: 317012, financed by the National Science Centre, Poland.

\section{References}

[1] Pawlak, W.; Wieleba, W.; Kluczyński, J. \& Śnieżek L. (2018). The influence of the addition of graphite on the tribological properties of polylactic (PLA) applied in 3D printing technology. Tribologia, Vol. 1/2018, 89-93, ISSN 0208-7774.

[2] Laski, P.A.; Takosoglu, J.E. \& Błasiak, S. (2015). Design of a 3-DOF tripod electro-pneumatic parallel manipulator. Robotics and Autonomous Systems,Vol. 72, 59-70, ISSN 0921-8890.

[3] Kozior, T.; Döpke, C.; Grimmelsmann, N.; Junger, I.J. \& Ehrmann A. (2018). Influence of fabric pretreatment on adhesion of three-dimensional printed material on textile substrates, Advances in Mechanical Engineering, 10 (8), 1-8.

[4] Budzik, G.; Burek, J.; Bazan A. \& Turek P. (2016). Analysis of the Accuracy of Reconstructed Two Teeth Models Manufactured Using the 3DP and FDM Technologies, Strojniski Vestnik - Journal of Mechanical Engineering, Vol. 62/2016, 11-20, ISSN 0039-2480.

[5] Rokicki, P.; Budzik, G.; Kubiak, K.; Bernaczek, J.; Dziubek, T.; Magniszewski, M.; Nowotnik, A.; Sieniawski, J.; Matysiak, H., Cygan, R. \& Trojan A. (2015). Rapid prototyping in manufacturing of core models of aircraft engine blades, Aircraft Engineering and Aerospace Technology, Vol. 86/2014, 323-327, ISSN 0002-2667.

[6] Adamczak, S.; Zmarzły, P.; Kozior, T. \& Gogolewski, D. (2017). Analysis of the dimensional accuracy of casting models manufactured by fused deposition modeling technology, 23rd International Conference Engineering Mechanics 2017, 66-69.

[7] Polak, R.; Sedlacek, F. \& Raz, K. (2017). Determination of FDM Printer Settings with Regard to Geometrical Accuracy, Proceedings of the 28th DAAAM International Symposium, pp.0561-0566, B. Katalinic (Ed.), Published by DAAAM International, ISBN 978-3-902734-11-2, ISSN 1726-9679, Vienna, Austria.

[8] Kundera, Cz. \& Bochnia, J. (2014). Investigating the stress relaxation of photopolymer O-ring seal models, Rapid Prototyping Journal, Vol. 20, Issue: 6, 533-540.

[9] Bartkowiak, J.; Lehner, J.; Hyde, J.; Wang, P.; Pedersen, D.B.; Hansem, H.N. \& Brown, C. (2015) Multi-scaleareal curvature analysis of fused deposition surfaces, Proceedings - Achieving Precision Tolerances in Additive Manufacturing, 77-82.

[10] Adamczak, S.; Zmarzły, P. \& Stępień, K. (2016). Identification and analysis of optimal method parameters of the V-block waviness measurements. Bull. Pol. Ac.: Tech. Vol. 64, No. 2, 325-332, ISSN 0239-7528.

[11] Adamczak, S.; Stepien, K. S. \& Zmarzly, P. (2017). An Analysis of Strategies of Measurement of 3D Rotary Elements, Proceedings of the 28th DAAAM International Symposium, pp.1096-1100, B. Katalinic (Ed.), Published by DAAAM International, ISBN 978-3-902734-11-2, ISSN 1726-9679, Vienna, Austria.

[12] Adamczak, S. \& Zmarzły, P. (2017). Influence of raceway waviness on the level of vibration in rolling-element bearings. Bull. Pol. Ac.: Tech. Vol. 65, No. 4, 541-551, ISSN 0239-7528.

[13] Brajlih, T.; Valentan, B.; Balic, J. \& Drstvensek. I. (2011). Speed and accuracy evaluation of additive manufacturing machine, Rapid Prototyping Journal, Vol. 17/2011, 64-75, ISSN: 1355-2546.

[14] http://www.stratasys.com, (2018), Accessed on: 2018-09-25.

[15] Farooqui, S.A.; Doiron, T. \& Sahay, Ch. (2009). Uncertainty analysis of cylindricity measurements using bootstrap method, Measurement, 42, 524-531.

[16] Zaborowski, A. (2010). Application of computer techniques for measurements of the shape and solid geometry errors in control of cylindrical components, Mechanik, Vol. 83, No. 11, 828-832.

[17] https://www.taylor-hobson.com/, (2018), Accessed on: 2018-09-25. 